\title{
Study on pyrexia in pregnancy and labour with special emphasis on fetomaternal outcome
}

\author{
Shabana Sultan, Reena Parihar, Poorva Badkur*
}

Department of Obstetrics and Gynecology, Gandhi Medical College, Bhopal, Madhya Pradesh, India

Received: 29 July 2020

Revised: 30 September 2020

Accepted: 08 October 2020

\author{
*Correspondence: \\ Dr. Poorva Badkur, \\ E-mail: poorvadoc@gmail.com
}

Copyright: () the author(s), publisher and licensee Medip Academy. This is an open-access article distributed under the terms of the Creative Commons Attribution Non-Commercial License, which permits unrestricted non-commercial use, distribution, and reproduction in any medium, provided the original work is properly cited.

\begin{abstract}
Background: Pyrexia in pregnancy is a very common clinical problem worldwide. Fever during pregnancy causes significant maternal and fetal complications. Fetus being an integral part of the feto-maternal unit and pregnancy involving numerous physiological changes and adaptations, pyrexia during the pregnancy affects both the mother and her foetus adversely. Effect of pyrexia on pregnancy depends on the extent of the rise in the temperature.

Methods: This is a prospective observational hospital-based study conducted over a period of 1 year from march 2018 to February 2019 Department of Obstetrics and Gynaecology, Sultania Zanana Hospital, Gandhi Medical College, Bhopal.

Results: Total no. of antenatal admission in Hospital during study period were 15354. Total 306 cases of pyrexia in pregnancy were found during the study period. Incidence of pyrexia in pregnancy in our study during study period was found $2 \%$.

Conclusions: The present study has demonstrated a need for multidisciplinary approach in cases of pregnancy complicated with pyrexia and also higher risk of maternal morbidity and mortality in un-booked patients. We found that pregnancy outcomes were good in booked cases with regular checkup. Early detection and management of patients with pyrexia can certainly help to improve maternal and fetal outcome. This also shows that multidisciplinary approach should extent throughout antenatal, intra-partum and postpartum period.
\end{abstract}

Keywords: Pyrexia, Pregnancy, Labour, Incidence

\section{INTRODUCTION}

Pyrexia in pregnancy is a very common clinical problem worldwide. Fever during pregnancy causes significant maternal and fetal complications.

Fetus being an integral part of the feto-maternal unit and pregnancy involving numerous physiological changes and adaptations, pyrexia during the pregnancy affects both the mother and her foetus adversely. Effect of pyrexia on pregnancy depends on the extent of the rise in the temperature.
Globally, pyrexia in pregnancy occurs as a common clinical problem and the feto-maternal risk is significantly elevated in pregnancy complicated by infection and fever. A wide range of maternal medical complications as well as fetal and neonatal complications occur due to pyrexia in pregnancy from various etiologies that range from preventable infections like malaria to hepatitis. Maternal complications were very much dependent on the etiology of fever however fetal outcomes overlapped irrespective of the cause of fever. Moreover, adverse fetal outcome was more numerous than maternal complication. Hence it can be hypothesized 
that hyperthermia related changes in the uterine environment can affect fetal well-being. ${ }^{1}$

Many cases of pyrexia in pregnancy have atypical and uncommon presentations which may be problematic for clinician in giving appropriate diagnosis and specific treatment. pyrexia from various etiology that ranges from preventable infection like malaria, dengue, typhoid, hepatitis results in adverse feto-maternal outcome. Therefore, standards methods of infection control in homes, communities and health care settings should be emphasised. $^{2}$

Therefore, some febrile diseases may take a more severe course in pregnancy leading to transplacental transmission of infectious agents and fetal jeopardy. Further, intrapartum fever in absence of infection has also been found to be associated with increased risk of developing neonatal hypoxic encephalopathy and unexplained neonatal seizures. . $^{3,4}$

Febrile illness in pregnancy may also occur due to infection. Pregnant women with febrile illness usually present with high temperature, sweating, shivering, headache, muscle ache, dehydration and fatigue. ${ }^{5}$

Maternal immune function is usually decreased in normal pregnancy and many of the potent antibiotics should be used with caution in pregnant women due to the risk of teratogenicity.

It has also been suggested that a maternal febrile episode can predispose to embryonic death, abortion, growth retardation, and defects of development and these defects might be caused by metabolic changes in the mother due to infections and fever, and not due to the associated elevation of temperature. ${ }^{6}$

\section{Aims and objectives}

Aim and objectives were to study incidence of pyrexia in pregnancy during the study period, to evaluate different causes of pyrexia in pregnancy and labor and to study effect of pyrexia in pregnancy on maternal and fetal outcome.

\section{METHODS}

This study was conducted in the department of obstetrics This is a prospective observational hospital-based study conducted over a period of 1 year from march 2018 to February 2019 Department of Obstetrics and Gynaecology, Sultania Zanana Hospital, Gandhi Medical College, Bhopal.

\section{Inclusion criteria}

All cases with pyrexia with pregnancy and labour admitted in Sultania Zanana Hospital Gandhi medical
College Bhopal during study period were included in the study.

\section{Exclusion criteria}

Include the fever due to septic abortions, blood transfusion reactions, diabetes mellitus, and cardiovascular disesases were excluded.

All relevant investigation pertaining to fever was done. All patients admitted with pyrexia in pregnancy and labour were followed till delivery for their maternofetaloutcome.

The main parameters of assessment include: incidence of fever in pregnancy, causes of fever, effects of episodes of fever on maternal and fetal outcomes, effect of specific infection on maternal and fetal outcomes and impact of fever on antepartum, intrapartum and postpartum phases.

Maternal complications in terms of postpartum hemorrhage (PPH), pneumonia, acute respiratory distress syndrome (ARDS), jaundice, septicaemia, post -operative infection, and other complications of specifics fever, maternal death was studied.

At the time of delivery birth weight of baby, gestational age at birth was studied. And the fetal outcome studied in terms of IUGR, pre-term, low birth weight, intrauterine fetal death (IUFD), refer to neonatal intensive care unit (NICU), neonatal and perinatal death. Collected data were entered in Microsoft excel spreadsheet and all the collected data were tabulated and analysed. Etiologies of pyrexia in pregnancy and various complications of maternal fever is analysed in form of proportions and percentages.

\section{RESULTS}

Details of the present study and observations are as follows:

There was a total of 110 babies in the study including 3 sets of twins. There were $46(41.8 \%)$ babies with IUGR. Eleven major adverse outcomes were noted in the study2 stillbirths, 6 babies required immediate respiratory support and three babies had respiratory distress subsequently.

Of the 6 babies who required immediate resusucitation, one expired in immediate neonatal period due to birth asphyxia (intrapartum fetal distress at 32 weeks in woman with severe preeclampsia), one expired after 10 days due to metabolic complications and the rest four survived.

Total no. of antenatal admission in Sultania Zanana Hospital during study period were 15354. 
Total 306 cases of pyrexia in pregnancy were found during the study period. Incidence of pyrexia in pregnancy in our study during study period was found $2 \%$ (Table 1).

Table 1: Incidence of pyrexia in pregnancy.

\begin{tabular}{|lll|}
$\begin{array}{l}\text { Total no of } \\
\text { antenatal }\end{array}$ & $\begin{array}{l}\text { Total cases of } \\
\text { pyrexia in } \\
\text { pregnancy } \\
\text { during the study } \\
\text { period }\end{array}$ & $\begin{array}{l}\text { Incidence of } \\
\text { antengatal } \\
\text { admission }\end{array}$ \\
\hline $\mathbf{1 5 3 5 4}$ & 306 & pregnancy \\
\hline
\end{tabular}

All the admitted pregnant women with fever $\geq 100.4^{\circ} \mathrm{F}$ once or $99.5^{\circ} \mathrm{F}$ on two occasion two hours apart were enrolled in the study after taking consent.

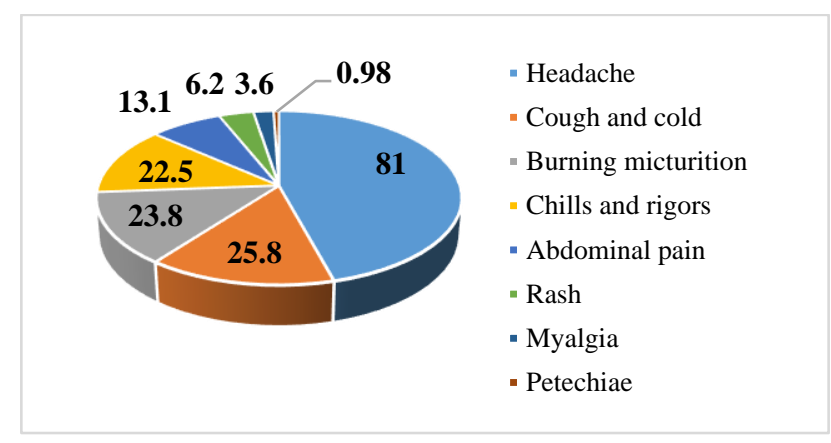

Figure 1: Distribution of patients according to symptomatology.

Data was collected from consenting females with written consents in their own language with the help of preformed tests and clinical questionnaire which contain age, demographics details, education status, parity, gestational age at the time of first episode of fever, duration of fever, and clinical pattern of fever and its variations by interview technique and their proforma was filled and then we follow the patient for their maternal and fetal outcome was coded appropriately and data collected was compile using MS excel and is expressed in form of percentage and proportion. All patient studied in detail with reference to pyrexia in pregnancy and labour, intervention required, mode of delivery, and fetomaternal outcome (Figure 1).

Headache $(81 \%)$ was the most common symptoms followed by burning micturition in $25.8 \%$, cough and cold in $23.8 \%$, chills and rigors in $22.5 \%$ and abdominal pain in $40(13.1 \%)$.

This (Figure 2) shows that most common cause of pyrexia in pregnancy is urinary tract infections (UTI) 85 (27.7\%), respiratory tract infections $77(25.1 \%)$, enteric fever $48(15.7 \%)$ and malaria $44(14.4 \%)$, chicken pox 19 (6.2\%). tuberculosis $14(4.6 \%)$, hepatitis $12(4 \%)$, dengue in $2(0.7)$ and pyrexia of unknown origin (PUO) in 4
(1.3\%). This shows that anatomical and physiological changes during pregnancy predisposes women to UTI.

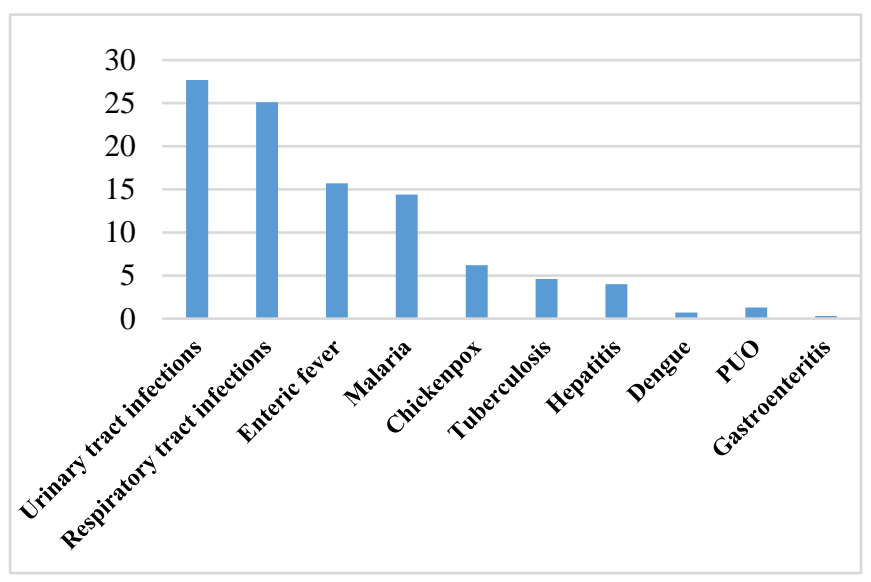

Figure 2: Distribution of patients according to type of fever.

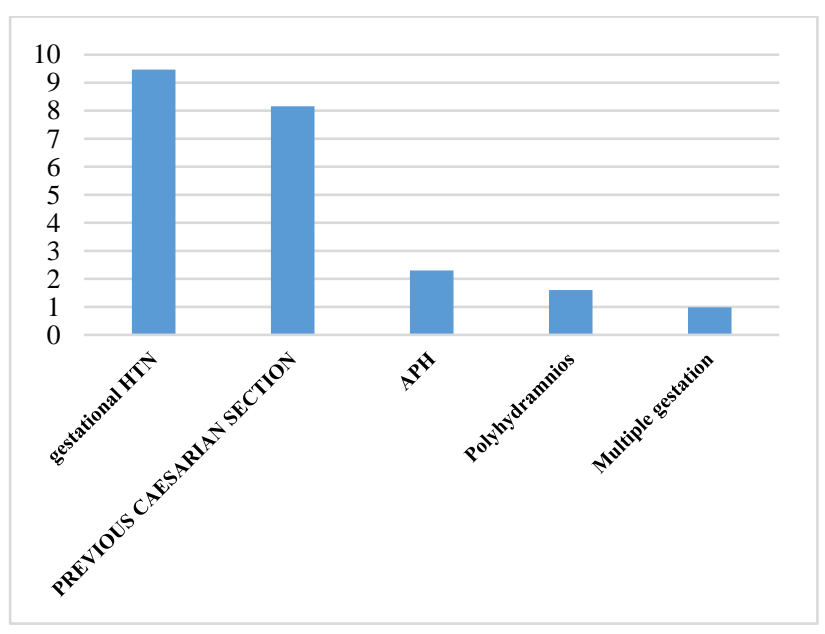

Figure 3: Associated obstetrics comorbidities.

This Figure 3 shows among 306 cases, 67 (21.89\%) cases have obstetrics co-morbidity. Out of which Gestational hypertension $29(9.47 \%)$ was most commonly seen. Previous caesarean section was $22(7.18 \%)$, APH in 7 $(2.3 \%)$, polyhydramnios in $4(1.63 \%)$ and multiple gestation was $4(0.3 \%)$.

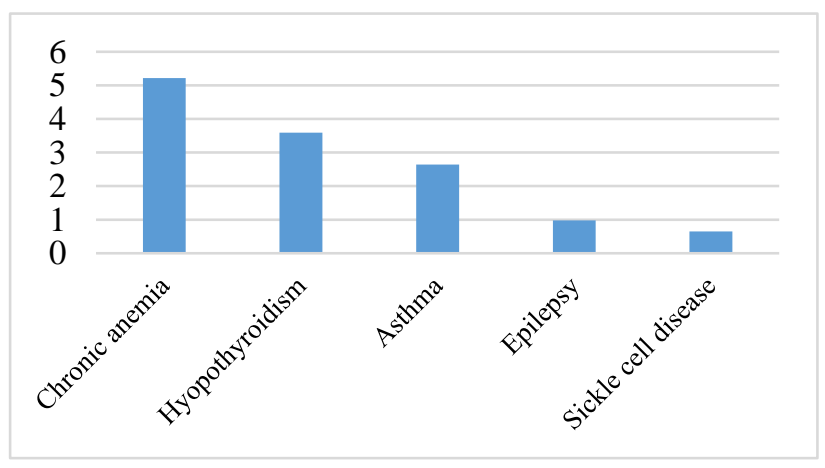

Figure 4: Associated medical comorbidities. 
This Figure 4 shows that anaemia $16(5.22 \%)$ and hypothyroidism $11(3.59 \%)$ were most common medical co-morbidity were seen.

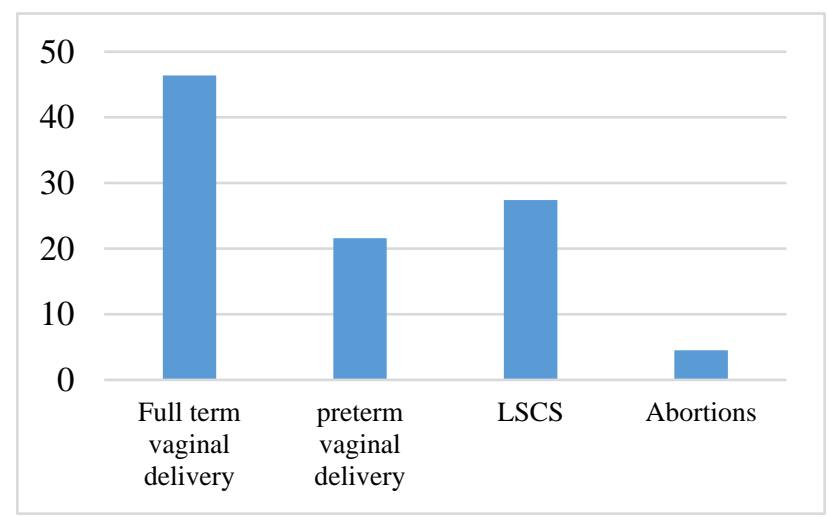

Figure 5: Distribution of patients according to outcome of pregnancy.

This Figure 5 shows that total vaginal delivery was 208 out of which $142(46.4 \%)$ were full term vaginal delivery and $66(21.6 \%)$ were preterm vaginal delivery. Caesarian section was $84(27.4 \%)$. Abortions were in $14(4.6 \%)$ cases.

\section{Distribution according to antepartum complications}

This Figure 6 shows that pre-term $66(21.56 \%)$ and PROM 36 (11.76\%) and fetal distress 31 (10.13\%), Oligo hydramnios $28(9.15 \%)$, anaemia in $21(6.86 \%)$ was the most common antepartum complication seen in patients with pyrexia with pregnancy. Other complication includes IUGR 15 (4.9\%) and hypoglycaemia 11 (3.59\%) and scar tenderness in $8(2.61 \%)$ cases.

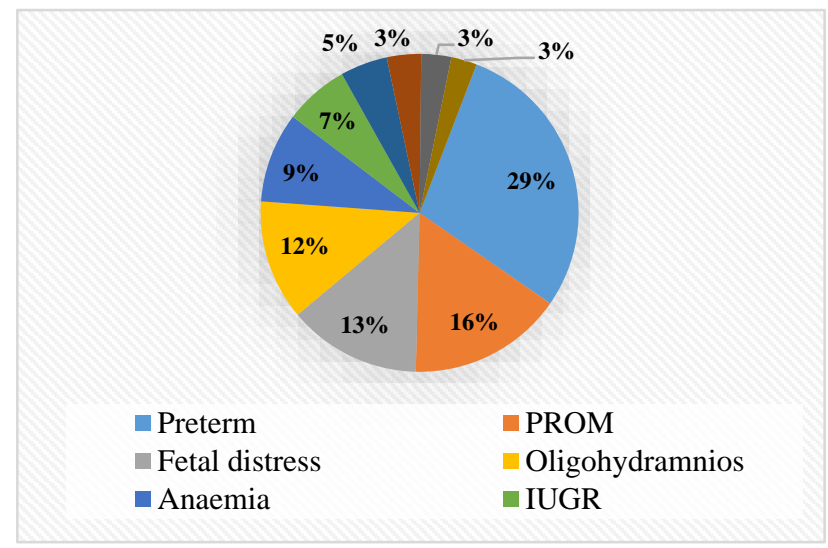

Figure 6: Distribution according to antepartum complications.

This Figure 7 shows that most common postpartum complication was surgical site infection $23(7.52 \%)$ and subinvolution 13 (4.25\%) and PPH 10 (3.27\%). Puerperal sepsis seen in $06(1.96 \%)$ cases.

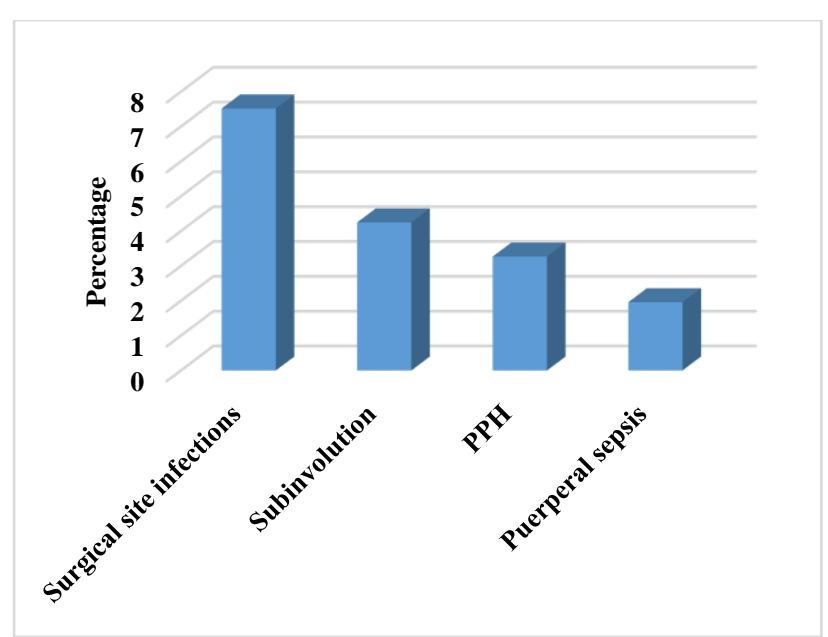

Figure 7: Distribution of patients according to postpartum complications.

This Figure 8 shows that ICU admission was in 121 cases $(39.54 \%)$, out of which severe morbidity and transfer to medicine department 26 (21.48\%), 95 (78.51\%) cases discharge in satisfactory condition and there was a mortality in $1(0.82 \%)$ case. Mortality was due to complicated malaria.

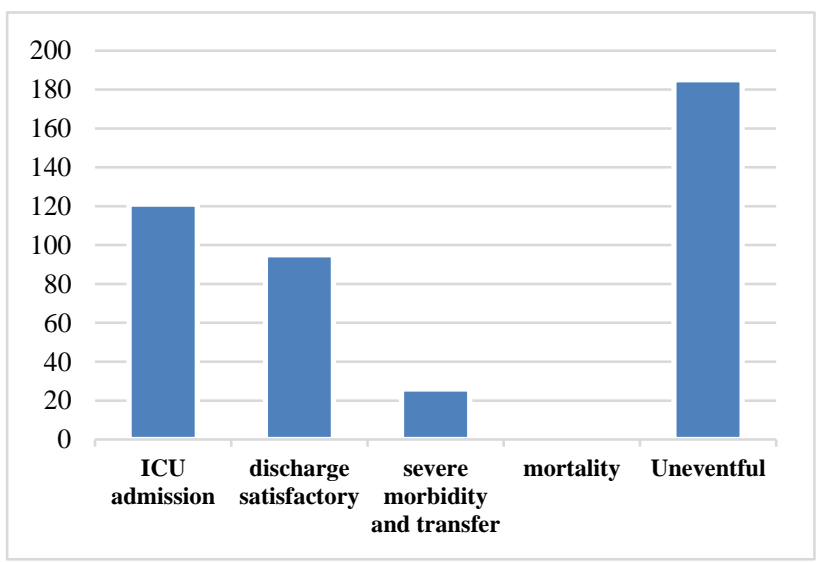

Figure 8: Distribution of maternal outcome.

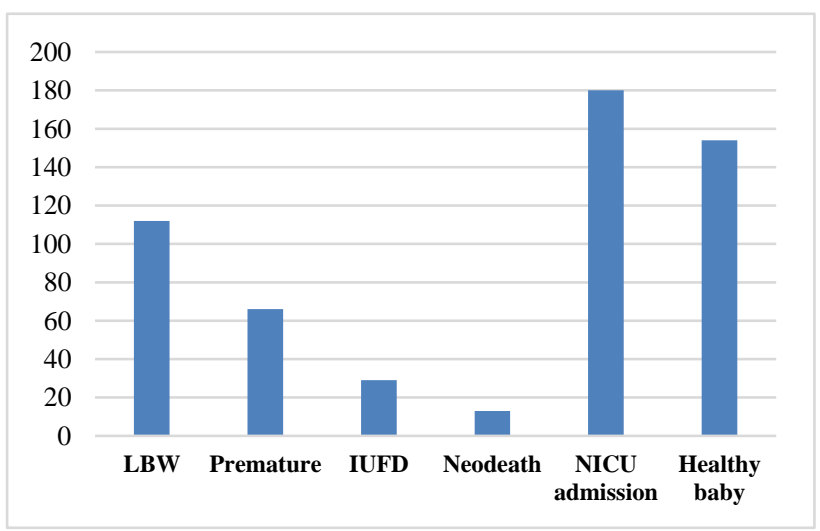

Figure 9: Distribution according to fetal outcome. 
This Figure 9 shows low birth weight 112 (36.6\%) most common fetal complications seen in pyrexia with pregnancy. Premature delivery was 66 (21.6\%). NICU admission $180(58.82 \%)$ and $29(9.5 \%)$ were stillbirth and $13(4.2 \%)$ were neo-death. This indicate that pyrexia in pregnancy has impact on fetal outcome depending on severity of febrile illness.

\section{DISCUSSION}

The study was aimed to evaluate incidence of pyrexia in pregnancy, different causes of pyrexia in pregnancy and labor and effect on fetomaternal outcome.

During our study, 306 patients of pyrexia in pregnancy was admitted over the period of 1 year fulfilling the inclusion criteria.

\section{Incidence of pyrexia in pregnancy}

In our study incidence of pyrexia in pregnancy was $2 \%$. This correlate with study done by Shrestha $\mathrm{N}$ et al $(3.15 \%){ }^{7}$ In contrast to my study higher incidence $(6 \%)$ was seen in study by MPoovathi et al. ${ }^{8}$ This is probably due to our centre being tertiary care centre located in centre of city so all type of low risk as well as high risk cases admitted here and admission rate is quite high (Table 1).

\section{Distribution according to symptomatology of patients}

In our study headache $81 \%$ was the most common symptom seen followed by burning micturition $25.8 \%$, cough and cold in $23.8 \%$ and chills and rigors in $22.5 \%$ and abdominal pain in $13.1 \%$ cases (Figure 1 ).

In another study by Chansamouth et al cough seen in 78 $(31 \%)$, dysuria $34(14 \%)$, diarrhea $27(11 \%)$, bleeding 14 $(6 \%)$, rash in $14(6 \%)$ and abdominal tenderness in $13(5 \%)$ cases. $^{7}$

In another study by Gehlot et al myalgia in $21(84 \%)$, headache $17(68 \%)$, skin rash $6(24 \%)$, Petechiae $3(12 \%)$ and Gum bleeding in 1 (4\%) cases. $^{9}$

\section{Type offever}

In our study most common cause of pyrexia in pregnancy is urinary tract infection $85(27.7 \%)$ followed by respiratory tract infection $77(25.1 \%)$ and Enteric Fever 48 (15.7\%) (Figure 2).

In study by Biswas et al most common cause of pyrexia in pregnancy was malaria $34.97 \%$ followed by UTI $21.31 \%$ and RTI $16.39 \% .^{1}$ Similarly, Nath studies that most common cause of pyrexia in pregnancy was malaria $21.6 \%$, UTI $20 \%$, dengue $17.2 \%$. In our study maximum cases of UTI were found which shows that anatomical and physiological changes during pregnancy predisposes pregnant women to urinary tract infection. ${ }^{2}$

\section{Associated obstetric and medical co-morbidities}

In our study among obstetric co-morbidities, gestational HTN $29(9.47 \%)$ was most commonly seen followed by Previous Caesarian section $22(7.18 \%)$ and APH 7 (2.3\%). Anemia 16 (5.22\%) and hypothyroidism $11(3.59 \%)$ were most common medical co-morbidities (Figure 3 and 4).

In contrast to my study, Vibha et al shows comparatively lower previous caesarian section $3 .^{10}$

In study by Poovathi et al higher incidence of gestational HTN 19 cases were seen. ${ }^{7}$

\section{Outcome of delivery}

In our study vaginal delivery were 208 out of which 142 $(46.4 \%)$ were full term vaginal delivery and $66(21.6 \%)$ were preterm vaginal delivery and LSCS was 84 (27.4\%) and abortions 14 (4.6\%) (Figure 5).

In study by Vibha et al comparatively lower proportion of caesarean section were seen $(13 \%){ }^{10}$

In our study incidence of abortion was $4.3 \%$, as compared to study conducted by More VS, Poovathi M et al where incidence of abortion was $14 \%$ and $13 \%$ respectively. ${ }^{8,10}$

\section{Antepartum complications}

In our study preterm, $66(21.56 \%)$, and PROM 36 $(11.76 \%)$, fetal distress $31(10.13 \%)$ and oligo hydramnios $28(9.15 \%)$ was the most common antepartum complication seen in patients with pyrexia in pregnancy. Anemia $21(6.86 \%)$ and IUGR seen in $15(4.9 \%)$ cases. In similar study Poovathi $\mathrm{M}$ et al preterm $28 \%$ was the most common complication followed by fetal distress $21 \%$ and oligohydramnios in $19 \%$. And anemia was in 41 cases. $^{8}$

This indicates that pyrexia in pregnancy causes preterm labor, IUGR, PROM and oligohydramnios hence it can be hypothesized that hyperthermia related changes in the uterine cavity affect the fetal wellbeing (Figure 6).

\section{Maternal outcome}

In our study there were $95(31.04 \%)$ ICU admission out of which $26(27.36 \%)$ cases transferred to medicine department due to severe morbidity and there is one mortality $1.05 \%$ seen due to complicated malaria and 211 $(68.96 \%)$ cases having uneventful outcome (Figure 8$)$.

Maternal mortality in our study was $1(1.05 \%)$, referred from PHC. Therefore, early referral and prompt critical care and management prevent in maternal death. 
In study by Poovathi et al maternal mortality was $25 \%$ most of that were associated with DIC, IUD and one or two combined risk factors. ${ }^{8}$

\section{Fetal outcome}

In our study low birth weight was most common 112 (36.6\%) fetal complication, pre term was 66 (21.6\%) and still birth seen in $29(9.5 \%)$ cases (Figure 9$)$.

Similarly, in study by Nath et al low birth weight $52.6 \%$ was the most common fetal complication seen while in study by Poovathi et al preterm and low birth weight $28 \%$ was most common fetal outcome.,

This signify that pyrexia in pregnancy has impact on fetal outcome depending on severity of febrile illness.

\section{CONCLUSION}

The present study was a hospital based prospective observational Conducted from march 2018 to February 2019 in Department of Obstetrics and Gynecology, Sultania Zanana Hospital, Gandhi Medical College, Bhopal has demonstrated a need for multidisciplinary approach in cases of pregnancy complicated with pyrexia and also higher risk of maternal morbidity and mortality in un-booked patients. We found that pregnancy outcomes were good in booked cases with regular checkup. Early detection and management of patients with pyrexia can can certainly help to improve maternal and fetal outcome. Pyrexia in pregnancy, a common clinical entity, results in wide range of maternal medical complications as well as fetal and neonatal complications. Duration of fever is linearly associated with poor outcomes. Preterm, IUGR, PROM, meconium stained amniotic fluid and abortions were most commonly seen. Different causes of fever had different impact on maternal and fetal outcome. Hence it is suggested that fever during pregnancy needs to be promptly investigated and treated to have a better outcome. One maternal death seen in our study were un-booked and late referred patients. This indicates that early referral from primary health centre and preventive measures help in preventing maternal mortality and neonatal mortality. Our study shows that despite having lack of awareness regarding complications of fever in pregnancy, awareness regarding family planning and birth spacing is low. Multigravida women were also seen in our study. This indicates need of awareness regarding family planning and birth spacing to further reduce maternal morbidity and mortality. Pyrexia from various etiologies that ranges from preventable infections results in adverse feto-maternal outcome. Therefore, standards method of infection control in home, communities, and healthcare settings, improving health education and awareness will go a long way in preventing such adverse feto-maternal outcomes.

Funding: No funding sources

Conflict of interest: None declared

Ethical approval: The study was approved by the Institutional Ethics Committee

\section{REFERENCES}

1. Biswas J, Banerjee K, Sanyal P, Datta M, Choudhury S, Dasgupta S, et al. Fetomaternal Outcome of Pyrexia in Pregnancy: A Prospective Study. Int J Womens Health Rep Sci. 2015;3(3):132-5.

2. Nath J, Mahajan S. A Clinical Study on Pyrexia in Pregnancy with Special Emphasis on Fetomaternal Outcome. Int J Sci Res. 2015;4(9):2071-74.

3. Impey L, Greenwood C. Fever in labour and neonatal encephalopathy: a prospective cohort study. Int J Obstet Gynaecol. 2010;108(9):594-7.

4. Lieberman E, Lang J, Richardson DK, Frigoletto FD, Heffner LJ, Cohen A. Intrapartum maternal fever and neonatal outcome. Pediat. 2000;105(1):8-13.

5. Fink JLW. Fever during pregnancy. Available at: https://www.thebump.com/a/fever-during-pregnancy. Accessed on 02 February 2020.

6. Maharaj D. Fever in Pregnancy. Antimicrobe: Infectious Disease Antimicrobial Agent. Available at: http://www.antimicrobe.org/e42.asp. Accessed on 25 February 2020.

7. Shrestha N, Thapa M. Etiology of Febrile Illness during Pregnancy. NJOG. 2019;5(1):37-9.

8. Poovathi M, Prasanna N. Fever in pregnancy and its maternal and fetal outcome at tertiary care level. Int $\mathbf{J}$ Reprod Contracept Obstet Gynecol. 2018;7:1864-7.

9. Gehlot H, Yadav OP, Sharma S, Nagar GG, Yadav A, Gupta PP. A study of dengue fever in pregnancy and its maternal and fetal prognosis. Int J Reprod Contracept Obstet Gynecol. 2017;6:3414-7.

10. More VS. Fever in pregnancy and its maternal and fetal outcomes. Int J Reprod Contracept Obstet Gynecol. 2017;6:5523-7.

Cite this article as: Sultan S, Parihar R, Badkur P. Study on pyrexia in pregnancy and labour with special emphasis on fetomaternal outcome. Int J Reprod Contracept Obstet Gynecol 2020;9:4414-9. 